\title{
OS PRÓTOMOS FEMININOS DE GELA: UMA PROPOSTA DE INTERPRETAÇÃO
}

\author{
Elaine Farias Veloso Hirata*
}

\begin{abstract}
HIRATA, E. F. V. Os prótomos femininos de Gela: uma proposta de interpretação. Rev. do Museu de Arqueologia e Etnologia. S. Paulo, 2:49-61, 1992.
\end{abstract}

RESUMO: Este trabalho analisa os principais contextos de utilização dos prótomos femininos em terracota em Gela, colônia ródio-cretense fundada no séc.VII a.C. na Sicilia, e Rodes, uma das metrópoles envolvidas nesta fundação. $\mathrm{O}$ estudo dos achados em santuários, necrópoles e áreas de habitação demonstrou uma especialização de função deste artefato na área colonial: os registros de prótomos em contexto funerário são insignificantes se comparados com o volume destes artefatos recuperados em santuários dedicados a Deméter e Core.

UNITERMOS: Prótomos Gregos - Arqueologia Mediterrânica Religião - Sicilia - Gela - Divindades Ctônias.

\section{O artefato: definição}

O termo prótomo, transcrito do grego $\pi \rho \circ \tau \mu \eta^{\prime}$, vem sendo utilizado para designar o artefato em terracota que - à semelhança de uma máscara - resulta da impressão de um rosto feminino em uma placa semicôncava de argila. (V. Pr. l)

O esquema iconográfico básico incorpora um véu que cobre a cabeça, desce sob a forma de duas faixas laterais e paralelas que reforçam a regiāo do pescoço terminando junto aos ombros. Variaçōes deste tipo original combinam a presença da stephane, ou do polos com brincos, colares, bem como múltiplos arranjos dos cabelos, por vezes visiveis na fronte ou junto às orelhas. (V. Pr. 2). ${ }^{1}$

(*) Museu de Arqueologia e Etnologia da Universidade de São Paulo.

(1) Uhlenbrock (1978: 25-26) estabelece uma tipologia básica para os prótomos gregos, a partir do arranjo do adorno de cabeça: no tipo "C" - "Covered" Type - a cabeleira não é visivel acima da testa; no tipo "U" -
Por conta da técnica de estampagem pela qual os prótomos eram produzidos, resultam peças vazadas, impressas só frontalmente, com paredes pouco espessas e, por consequência, leves o suficiente para que pudessem ser suspensas. Para tanto, a grande maioria vem dotada de um ou mais orificios destinados a este fim. A presença destes dispositivos para sustentação é interpretada por $M$. Bell (1981:86) como indicativo seguro de uma funçāo prioritariamente votiva e não funerária. ${ }^{2}$

As dimensões dos prótomos variam mui-

\footnotetext{
"Uncovered" Type - percebem-se variados arranjos do cabelo e a sobreposicão da stephane ou polos. O tipo " $\mathrm{C}$ " é o mais comum, correspondendo aos exemplares mais antigos oriundos de centros produtores da Grécia de Leste. ("Tipo Ródio).

(2) Sobre a função e o significado de prótomos - tema que será retomado ao longo deste artigo - Barra Bagnasco (1986: 133-145) elaborou uma sintese critica extremamente útil e abrangente; enfocando o problema a partir da questão das origens, Uhlenbrock (1978: 10-24) também contribuiu decisivamente para a discussão.
} 
to: há peças que não chegam a ultrapassar 10 $\mathrm{cm}$, enquanto outras atingem o tamanho natural (Orlandini, 1968: 37; fig. 19). Como é usual acontecer entre as terracotas, pouco restou da policromia original. Nos raros exemplares que ainda exibem as cores originais (Clara Rhodos, 1931; pl. IV), percebe-se o uso deste recurso para indicar detalhes anatômicos como sobrancelhas e pupilas, adornos, como colares ou brincos ou então as dobras da vestimenta. Ao estudar os prótomos da Grécia continental e insular, sob um enfoque estilistico, F. Croissant relativiza a importância da decoraçāo pintada: ..."trata-se de um "coloriage" estereotipado e convencional, destinado mais a sublinhar as articulações morfológicas do que a enriquecer a estrutura plástica de nuances propriamente pictóricas" (Croissant, 1983:17). Ainda que esta afirmativa de Croissant pudesse ser comprovada em um número significativo de documentos, em vários locais de achado, restaria uma possibilidade concreta de que atributos identificadores da representação poderiam ter se perdido juntamente com a policromia. Assim, como exemplo, a presença de tipos especificos de colares, brincos; flores, frutos, animais tenderiam a sugerir associações com categorias precisas de divindades (Sguaitamatti, 1984:52-59).

No quadro da coroplastia grega, os prótomos representam, ainda hoje, uma questāo controversa ${ }^{3}$. Surgem na $2^{\mathrm{a}}$ metade do século VI a.C. quase que restritos a contextos votivos e funerários da ilha de Rodes (Blinkenberg, 1931); conhecem uma rápida e notável expansão por todo o Mediterrâneo, chegando a atingir as costas do Mar Negro ainda nos últimos anos do mesmo século (Uhlenbrock, 1978: 26 e seg.); já no decorrer do século V, a produção diminui drasticamente na maioria das regiōes e em alguns sitios siciliotas como Agrigento, à retração da ocorrência dos prótomos corresponde uma aceleração na manu-

(3) Para tanto coniribui a total ausência de referências diretas aos prótomos nas fontes escritas: nào sabemos siquer como os gregos antigos os nomearam. O uso do termo $\pi$ рото $\mu \eta^{\prime}$ é simplesmente convencional, por analogia ao seu sentido usual de "busto". Quanto aos documentos figurados: pintura funerária do Museu de Tessalònica, datada do final do século $\mathrm{V}$, retratando um prótomo suspenso junto a um muro e fragmento de estatueta feminina segurando um prótomo (Croissant 1983:1). fatura de bustos femininos considerados, pela maioria dos especialistas, seus sucessores naturais (Kilmer, 1977).

Esta rápida trajetória significou, no entanto, a presença marcante dos prótomos, a partir do final do século VI, como uma das mais frequentes categorias de oferendas votivas em santuários de divindades femininas especialmente no Ocidente grego. ${ }^{4}$

A investigação científica vem buscando esclarecer a origem e o significado dos prótomos estabelecendo paralelismos iconográficos, estilisticos e simbólicos com documentos contemporâneos tanto em áreas de expansão da cultura grega no Mediterrâneo quanto em ambiente púnico, tendo em vista não só a presença do prótomo neste contexto, mas a analogia entre as divindades a quem gregos e púnicos ofertaram estes artefatos: Tanit e Deméter-Core (Bisi, 1966: 46).

\section{O artefato: contextualização}

No sítio de Rodes (V. Pr.3) ocorreu, pela primeira vez, no inicio deste século, a recuperação de um notável volume de prótomos: mais de seiscentos exemplares, integrando um depósito vizinho ao templo de Atena Lindia, na acrópole (Blinkenberg, 1931: 23-27, prs. 114 a 120). A estes, somaram-se cerca de 160 , localizados nos arredores de Lindos. A par deste conjunto, numericamente tão siginificativo $^{5}$, vários prótomos foram descobertos, na mesma época, tanto na favissa do Heraion de Delos (Laumonier, 1956) quanto na necrópole de Samos. A proliferação dos achados ocorreu a partir dos anos 30 , incluindo sitios por todo o Mediterrâneo e também as costas do Mar Negro. Em Olbia, foram documentados em

(4) Uhlenbrock (1978:26-53) lista os sitios onde há registro de ocorrência de prótomos em áreas da Grécia continental e insular, Ásia Menor, Palestina, norte da África, Mar Negro e Sicilia; Barra Bagnasco (1986: 144-45) relaciona os achados da Magna Grécia e Sicilia.

(5) O volume extraordinário dos achados em Lindos, Camiros e Iálisos levou os arqueólogos a considerarem os prótomos como produtos especificamente ródios. $O$ estudo de F. Croissant (1983: Il e ss.) demonstra a necessidade de serem revistas estas posiçōes em função das novas descobertas (Tasos, por exemplo) e sugere a existência de vários centros de produçào na Grécia de Leste. 
contexto votivo - santuário de Deméter - e na penisula de Taman, em uma área sagrada, cujo culto não foi identificado.

Um levantamento sumário dos principais centros de ocorrência de prótomos femininos no Mediterrâneo indica uma expressiva concentração destes na Sicilia. Levando-se em conta o critério quantitativo, os sítios de Selinonte, Gela, Agrigento, Siracusa e suas áreas de influência no interior (como Grammichele, Sabucina) destacam-se como os grandes centros produtores da Sicilia.

A maioria dos estudiosos data os primeiros prótomos femininos produzidos em sítios da Jônia na $2^{\mathrm{a}}$ metade do século VI a.C. (por exemplo, Laumonier, 1956:73; Orlandini, 1963: 10; Uhlenbrock, 1978:72 e B.Bagnasco, 1986:138). Esta datação apoia-se, seja na associação com material cerâmico, hoje exaustivamente estudado, ou então em comparaçōes com a estatuária ou a coroplastia contemporànea. Usando de tais critérios, Croissant (1983: 236 e ss.) recua a 570 a.C. a cronologia para os tipos originários da Ática, o que equivale, na prática, a admitir que não seriam os sitios jônicos os primeiros a produzi-los e utilizá-los embora numericamente os prótomos "de tipo Ródio" sejam amplamente superiores aos áti$\cos$ e a sua distribuição geográfica muito mais abrangente. ${ }^{6}$

O tipo básico do prótomo feminino (V. Pr.l) começa a sofrer alteraçōes já no final do século VI, quando os ombros e os braços passam a integrar a representação inicial. A evolução subsequente dará origem aos bustos femininos (Kilmer, 1977: 3; Barra Bagnasco, 1986: 66), categoria bastante documentada nos sitios siciliotas de Agrigento, Gela, Morgantina e Siracusa e na Itália do Sul: Locres e Medma, por exemplo. Os bustos femininos quase sempre ornados com o polos, continuam a ser

(6) O presente estudo não comporta uma discussão maior sobre as questões subjacentes aos diferentes arranjos tipológicos que os autores vêm propondo no tratamento dos prótomos. Assim, veja-se, por exemplo, a publicaçāo de F. Croissant (1983), que aprofunda os estudos estilisticos referentes a prótomos da Grécia metropolitana, criando uma complexa tipologia que tem servido de referencial para estudos nesta linha de interpretaçāo; Barra Bagnasco, por sua vez, estabelece uma tipologia adaptada à situação especifica dos prótomos locrenses, ressaltando as analogias com a escultura(B. Bagnasco, 1986: 25-104). produzidos aproximadamente durante três séculos, o que contrasta com a efêmera passagem dos prótomos pela coroplastia antiga. $O$ depósito votivo do santuário de Lindos, em Rodes, configura uma situação excepcional, ao registrar a continuidade na ocorrência dos prótomos, chegando até o século III a.C. ${ }^{7}$

À medida que se multiplicam as escavaçōes na bacia do Mediterrâneo, aumentam proporcionalmente as descobertas dos prótomos, especialmente nos estratos arqueológicos correspondentes ao final do século VI a.C.. Em geral, ocorrem em santuários dedicados a divindades femininas. E o caso de Delos, no Heraion; em Tasos, na área consagrada a Ártemis; no Afrodision de Argos; em Locres, no santuário dedicado a Perséfone e nos inúmeros centros de culto siciliotas identificados com Deméter e Core. Neste último caso, há que se ressaltar o fato de ser no Thesmophorion de Bitalemi (Gela), isto é, no tipo de santuário indiscutivelmente dedicado a Deméter, que são registrados os mais volumosos achados de prótomos femininos da ilha (Orlandini, 1966).

Em escala bem mais reduzida são as descobertas em contexto funerário; Rodes, Samos e Tera são alguns exemplos desta ocorrência, raramente atestada, por outro lado, nas necrópoles da Sicilia (Uhlenbrock, 1978:52).

Nas áreas habitacionais, os prótomos são inexpressivos enquanto ocorrência; destacamse, como exceção, o sítio grego de Olinto e, na Sicilia, Morgantina.

O caso de Olinto (Robinson, 1933:1-13), configura uma situação atípica em relação aos relatos de achados de prótomos já publicados até o momento. De inicio, surpreende a sua recorrência nas áreas habitacionais, comparando-se com as necrópoles, onde preferencialmente constatam-se as estatuetas (Robinson, 1933: 10-13). Por outro lado, a única inscrição descoberta nas terracotas de Olinto encontra-se justamente em um busto feminino do século V e compōe-se da silaba $\Delta \eta$. Robinson identifica-a seja com uma dedicatória a Deméter (ou Despoina) ou entāo com a assinatura do fabricante (Robinson, 1933:9).

(7) Paolo Orsi (Not.Sc., 1913) reconhece no busto uma projeção tridimensional do prótomo e aponta para o processo de transformaçāo formal do prótomo para o busto. 
Em Morgantina foram descobertos três prótomos em habitaçōes datadas do final do periodo arcaico (Bell, 1981: 86). Estabelecendo um paralelo com os achados de Olinto, Bell concorda com Robinson e atribui esta presença ao sentido apotropaico de que estariam imbuidos os prótomos, ao serem dependurados nos muros das residências (Robinson, 1933: 9-12; Bell, 1981: 86).

Este é, em sintese, o quadro atual correspondente aos achados noticiados nos sitios do Mediterrâneo. Há que se colocar, no entanto, uma questão nem sempre apresentada de forma transparente pelos arqueólogos: a porcentagem de áreas sagradas escavadas é francamente superior tanto às necrópoles quanto às zonas de habitação, em especial no que tange aos periodos mais recuados. Nesta perspectiva, a cautela se impōe como procedimento indispensável para que generalizaçōes apressadas não venham a comprometer a busca do sentido destes artefatos no âmbito da cultura grega antiga.

\section{A origem e significado dos prótomos}

A questão da origem dos prótomos divide os especialistas: para uns, trata-se de um processo de desenvolvimento interno da arte grega, a partir de cabecinhas de estilo Dedálico aplicadas aos vasos (Smith, 1949: 356). Outros, no entanto, apontam para analogias e paralelismos formais e simbólicos com produtos (máscaras em geral) egipcios, cipriotas ou púnicos (Blinkenberg, 1931; Laumonier, 1956; Bell, 1981) para fundamentar a hipótese de um protótipo não grego. ${ }^{8}$

Os especialistas que desde os finais do século passado buscaram discutir o significado dos prótomos enfocaram basicamente duas grandes áreas de problemas relacionados com

(8) Uma discussão sobre "o" local de origem dos prółomos - por tratar-se de questão muito complexa e controversa - nos distanciaria do objetivo principal deste trabalho, i.é., analisar o significado deste artefato a partir de parâmetros histórico-culturais especificos. Nesta perspectiva, nos limitaremos a citar alguns estudos mais recentes e que sinalizam para novos enfoques em relação ao problema. Sinteses de posições assumidas pelos especialistas poderão ser encontradas nos trabalhos de Uhlenbrock (1978: 15-24) e também por B. Bagnasco (1986: 134-137). a identificação e interpretação da imagem representada - divindade? fiel? o morto? - e com uma explicação para as caracteristicas formais - objeto com orificios de sustentação, vazado, impróprio para uso como máscara incomuns até então na tradição figurativa grega (Barra Bagnasco, 1986:150-157).

A maioria destes estudos, no entanto, releva a rede de relaçōes interativas entre o prótomo e o sistema cultural em que está inserido. Assim, são poucos os trabalhos que circunscrevem um corpus documental coerente, tanto do ponto de vista cronológico quanto espacial e, a partir dai, aprofundam a problemática relativa ao significado deste artefato. Uhlenbock, Bell e Barra Bagnasco situam-se neste tipo de abordagem, o que resultou em interessantes conclusōes sobre os prótomos de Gela, Morgantina e Locres.

Em sintese, entendemos que é indispensável a multiplicação dos estudos de caso para que as várias soluçōes adotadas em relação aos prótomos possam ser levadas em conta na elaboração de uma interpretação mais ampla.

No caso especifico do Ocidente grego será fundamental compreender o prótomo como um componente significativo no conjunto formado por um sistema cultural de alta complexidade, como é o caso de um núcleo colonial. O seu valor simbólico não poderá ser dissociado do quadro especifico da Sicilia, dos vários momentos políticos em que as tiranias manipularam a religião não só como um meio de projeção pessoal, mas também como um elemento de aproximação com as populações indígenas.

Assim, o exame detalhado dos vários contextos de utilização dos prótomos em cada colônia e do seu relacionamento com as outras categorias de oferendas votivas e funerárias tornará possivel uma compreensão mais ampla do sentido que este ex voto assume no contexto siciliota; se há continuidade de uma prática religiosa metropolitana ou se, pelo contrário, ocorre uma reelaboração e adaptação exigidas pela nova situação histórica que se apresenta aos colonos.

\section{Um estudo de caso: Gela}

A constatação de que a maioria dos autores procurou interpretar os prótomos a partir 
de uma visão compartimentada da sociedade, generalizando os resultados para outras situaçōes histórico-culturais, levou-nos a optar por um estudo pontual, restrito a um único sítio: Gela. (V. Pr.4)

Fundada em 688 por colonos ródios e cretenses, Gela logo assumiu um papel preponderante na transmissão de componentes culturais jônicos nas áreas siciliotas sob sua influência. A alta incidência de prótomos nos santuários gelenses vem sendo constatada desde as primeiras escavaçōes na área, datadas do final do século XIX.

A dependência de Gela em relação aos padrōes estilisticos e formais jônicos ${ }^{9}$, que se percebe na análise dos prótomos, coloca um problema fundamental para a própria definição do sentido deste artefato: esta dependência significaria a adoção simultânea das mesmas formas de utilização? Colocando a questão em outros termos: a importação e assimilação de convenções figurativas teria implicado na incorporação do simbolismo originário de que estariam revestidos os prótomos, em área jônica?

Definida esta hipótese de trabalho, o estudo encaminhou-se no sentido de explicitar e caracterizar os contextos preferenciais de utilização dos prótomos e, na mesma perspectiva, situar possiveis áreas de exclusão, para que, em uma sintese final, o quadro da distribuição espacial dos prótomos em Gela, pudesse ser comparado com os dados relativos a Rodes.

O levantamento exaustivo dos locais de achado dos prótomos femininos em Gela, abrangendo santuários, necrópoles e áreas habitacionais, permite que se proponha o seguinte quadro da sua distribuição espacial durante

9) A extraordinária dependência de Gela em relaçào à cultura figurativa jônica em geral - veja-se o caso das terracotas - e, em especial aos modelos ródios, poderia corresponder, em primeira instância, a uma ausência, na Sicilia, de uma tradição específica nesta área, marcante o suficiente para promover uma assimilação por parte dos recém-chegados. Esta dependência, no entanto, com o passar do tempo deveria diminuir, dando ensejo à criaçào de uma tradição figurativa própria, a partir dos padrōes estilisticos importados. Este fenòmeno, no entanto, nào ocorreu em Gela: até meados do século $\mathrm{V}$ a produção coroplástica gelense reproduz os principais tipos importados da Grécia de Leste. o periodo que vai do final do séc. VI até a metade do V a.C:

Os grandes santuários localizados na Acrópole e dedicados a divindades poliades como Atena Lindia ${ }^{10}$ e Hera apresentam como oferenda típica os vasos cerâmicos e as estatuetas de terracota. A ocorrência de prótomos é percentualmente insignificante em relaçāo aos outros exvotos (Notizie Scavi 1962:340408).

O principal contexto de utiliação dos prótomos em Gela é constituído por centros de culto especificos: trata-se de pequenos santuários de construção simples, ou mesmo isentos de qualquer estrutura arquitetônica, limitandose à presença de fossas com oferendas e restos de sacrificios. Localizam-se, em geral, fora da cinta murada que delimita o núcleo urbano, integrando-se às regiōes agricolas e pastoris, à chora. É o caso de Predio Sola, Feudo Nobile, Bitalemi (Orlandini, 1968:33-44)(V. Pr.5).

Os prótomos são também documentados nos santuários localizados nas fronteiras da chora gelense, e nos centros indigenas helenizados do interior como Grammichele, Monte Saraceno, Sabucina, dentre outros. A proliferação de áreas de culto com características arquitetônicas de "tipo grego" (métopas, por exemplo) coincide com um movimento expansionista de Gela, a partir do final do séc. VII, pressionada pelas novas levas de colonos que não cessam de chegar à Sicília.

Em qualquer dos santuários citados a presença dos prótomos se faz sempre em associação com outros tipos de oferenda comuns nos centros de culto dedicados às "Duas Deusas": Deméter e Coré. Trata-se de estatuetas de terracota segurando o porquinho (Sguaitamatti, 1984), o archote, a romã, hidrias miniaturisticas, lamparinas de terracota, kernoi, representações em argila dos órgãos sexuais, de flores e frutos (Rolley, 1965). Evidencia-se

(10) No Santuário de Atena Lindia, contruido pelos colonos ródio-cretenses na Acrópole por eles próprios denominada Lindioi, não há registro de prótomos em número significativo. Por outro lado, é bastante plausivel que a figurinha em terracota denominada "Atena Lindia" - inexistente em Rodes e tão frequente nos santuários siciliotas - tenha sido um tipo coroplástico puramente gelense, criado a partir da cópia da antiga estátua de culto do santuário de Lindos. 
HIRATA, E. F. V. Os prótomos femininos de Gela: uma proposta de interpretaçāo. Rev. do Museu de Arqueologia e Etnologia, S. Paulo, 2:49-61, 1992.

uma relação estreita entre os santuários atribuídos a Deméter-Core e a presença dos prótomos como oferenda votiva recorrente. $\mathrm{O}$ exemplo mais expressivo é o Thesmophorion de Bitalemi, onde os prótomos constituem o ex voto característico de todo um estrato arqueológico.

Nos quarteirões de habitação e nas necrópoles gelenses não se registram achados de prótomos. A oferenda funerária mais abundante é a cerâmica. A exclusão de prótomos em contexto funerário representa uma particularidade extremamente importante significativa de Gela em relação à metrópole ródia.

Como já foi apontado de início, a distribuição espacial dos prótomos em Rodes indicava uma função dupla: votiva, na maioria dos casos e funerária, secundariamente. Os dados disponiveis sobre as necrópoles referem-se ao sitio de Fikellura, onde aproximadamente 300 sepulturas, datadas entre $510-410$ a.C. foram escavadas. Destas, cerca de 50 possuiam estatuetas e/ou prótomos de terracota em seu mobiliário funerário, embora a cerâmica ainda se destaque como o exvoto característico. Em aproximadamente $20 \%$ das tumbas que exibem terracotas (onze), documentam-se os prótomos, sendo que em duas registram-se mais de um exemplar.

A análise do conjunto das oferendas nas sepulturas "com prótomos" permite constatar que se trata daquelas que dispõem de um mobiliário funerário mais rico: das onze tumbas, seis apresentavam mais de dez objetos. Esta é uma alta concentração, tendo em vista que a maioria das sepulturas com terracotas comportava de duas a, no máximo, oito ofertas funerárias. No caso de um sepultamento infantil, datado do final do séc. VI, de um total de 7 objetos, 3 eram prótomos femininos.

Assim, muito embora em Gela os prótomos reproduzissem com fidelidade os padrões de representação ródios, há que se supor um posicionamento particular no que diz respeito à função. Em sintese, objetos análogos, do ponto de vista morfológico e estilistico e contemporâneos, foram utilizados em contextos diferentes na metrópole e colônia, o que permite inferir, neste caso, uma especialização de significado na colônia.

Uma hipótese poderá ser levantada a partir destes dados: o santuário gelense de Atena
Lindia remonta aos primeiros tempos da vida da colônia. De acordo com a datação cerâmica associada é possivel considerá-lo o mais antigo centro de culto da cidade: extremo final do séc. VIII, inicio do séc. VII a.C. Nesta época,os prótomos não são documentados mesmo no santuário de Rodes, onde surgem, como foi visto, a partir da segunda metade do séc. VI a.C. Justamente nesta época, é perceptivel um alastramento dos centros de culto não-urbanos em vários pontos da chora gelense coincidindo com o avanço dos colonos em direção ao interior da ilha na busca das terras férteis da planicie, bem como atraídos pelas possibilidades de trocas comerciais com os indígenas.

Os prótomos, introduzidos em Gela nos finais do séc. VI, não teriam sido deliberadamente associados aos cultos de Deméter e Core, que, a partir do séc. VI são muito incentivados, deixando de ser o culto familiar dos Deinomênidas ${ }^{11}$ para assumir um papel preponderante no processo de crescimento político da colônia? (White, 1964).

A especificidade do prótomo como oferenda votiva nos santuários dedicados a Deméter-Core em Gela explica também a sua absoluta ausência nas necrópoles gelenses, ao contrário do que ocorria nāo só em Rodes, como também nas sepulturas de Samos, Tera, Delos e localidades da Beócia e Fócida.

Os achados de prótomos nos sítios do Egeu, da Grécia propriamente dita, das colônias do Mar Negro evidenciam, como já apontamos, oferendas em santuários de divindades femininas variadas. No caso de Gela, no entanto, foi possivel precisar, a partir da análise dos santuários, das divindades cultuadas e do relacionamento do prótomo com as oferendas tipicas de cada um destes centros de culto, um paralelismo claro entre a prática de ofertar prótomos e os cultos de Deméter-Core.

Assim, o dado fundamental que transparece da análise da distribuição espacial dos prótomos em Gela é a sua exclusão, de maneira sistemática, de contextos que não sejam definidos como centros de culto às divindades

(11) O relato de Heródoto (VII, 153) a respeito da fundaçāo de Gela menciona Telines, personagem que teria acompanhado o oikistés Antifemo e seria possuidor dos "objetos sagrados das divinidades ctônias"; tal privilégio possibilitaria a Telines aplacar uma sublevaçào do demos gelense contra a aristocracia local (os Gamoroi). A partir 
do mundo subterrâneo e a sua presença marcante e maciça quando outros elementos comprovam, de maneira inequívoca, a conotação ctônia do santuário. Tal é o caso do Thesmophorion de Bitalemi e do centro de culto denominado "Predio Sola".

O Themosphorion de Bitalemi revela-se como exemplo mais expressivo: é, até o momento, o único santuário escavado na Sicilia onde se pôde comprovar a realização das Thesmophorias, a mais importante das festas em honra de Deméter. É nesta santuário que os prótomos são encontrados, na expressão de Orsi, "a migliaia".

No caso de Predio Sola, o paralelismo com Bitalemi é grande: lamparinas caracterizando um estrato, do mesmo modo que os prótomos particularizam o outro; a presença de balsamários em forma de genitais que pode ser aproximada do costume de ofertar os myllói ${ }^{12}$ durante as Thesmophorias. As lamparinas teriam, além da conotação votiva, uma função prática no caso das cerimônias noturnas, como as que se desenvolviam na festa das semeaduras de outono.

Em síntese, a análise dos achados em Gela permite que se constate uma especialização do uso dos prótomos tanto em relação à metrópole ródia quanto à situação geral dos sitios gregos. Ao deixar de ter a dupla conotação votiva/funerária afirma-se como uma oferenda expressiva de uma divindade particular: Deméter.

$\mathrm{O}$ encaminhamento metodológico deste trabalho, tendo como ponto de partida a explicitação da distribuição espacial dos prótomos em Gela e determinando contextos preferenciais de utilização e contextos de exclusão, não poderia, evidentemente pretender a resolução de um problema complexo como a função dos prótomos femininos em geral. A partir, no entanto, da comparação dos resultados deste e de trabalhos análogos a ele, enfocando as principais cidades que produziram e utilizaram prótomos no mundo grego, será possivel propor, com segurança, uma interpretação ampla e abrangente do próprio sentido do objeto em si.

(12) Os myllói eram bolos ou pães feitos com gergelim e mel, com a forma dos órgāos genitais. Durante as Thesmophorias os myllói eram ofertados a Deméter-Core (Ciaceri, 1911: 198). 
HIRATA, E. F. V. Os prótomos femininos de Gela: uma proposta de interpretaçāo. Rev. do Museu de Arqueologia e Etmologia, S. Paulo, 2:49-61, 1992.

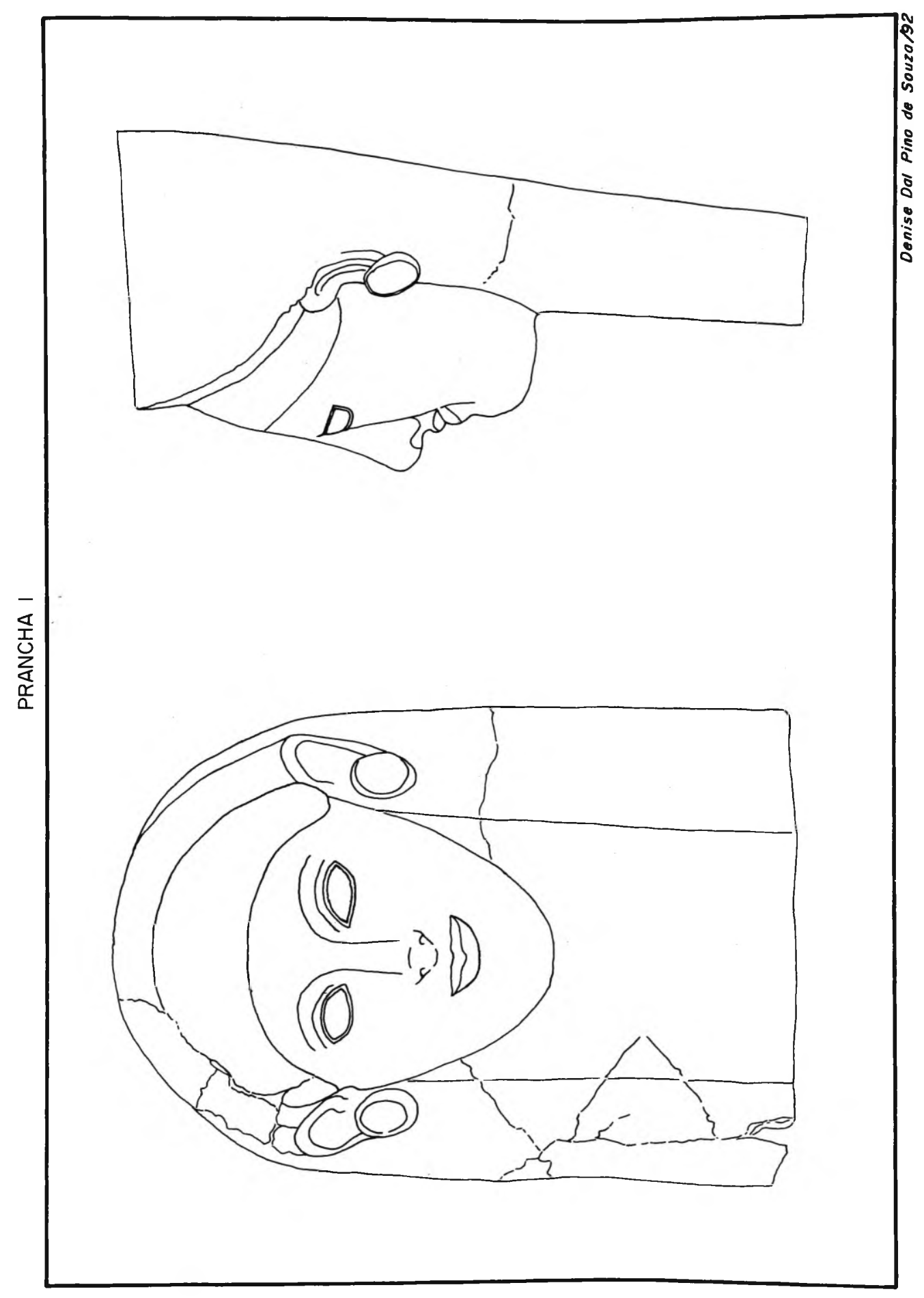




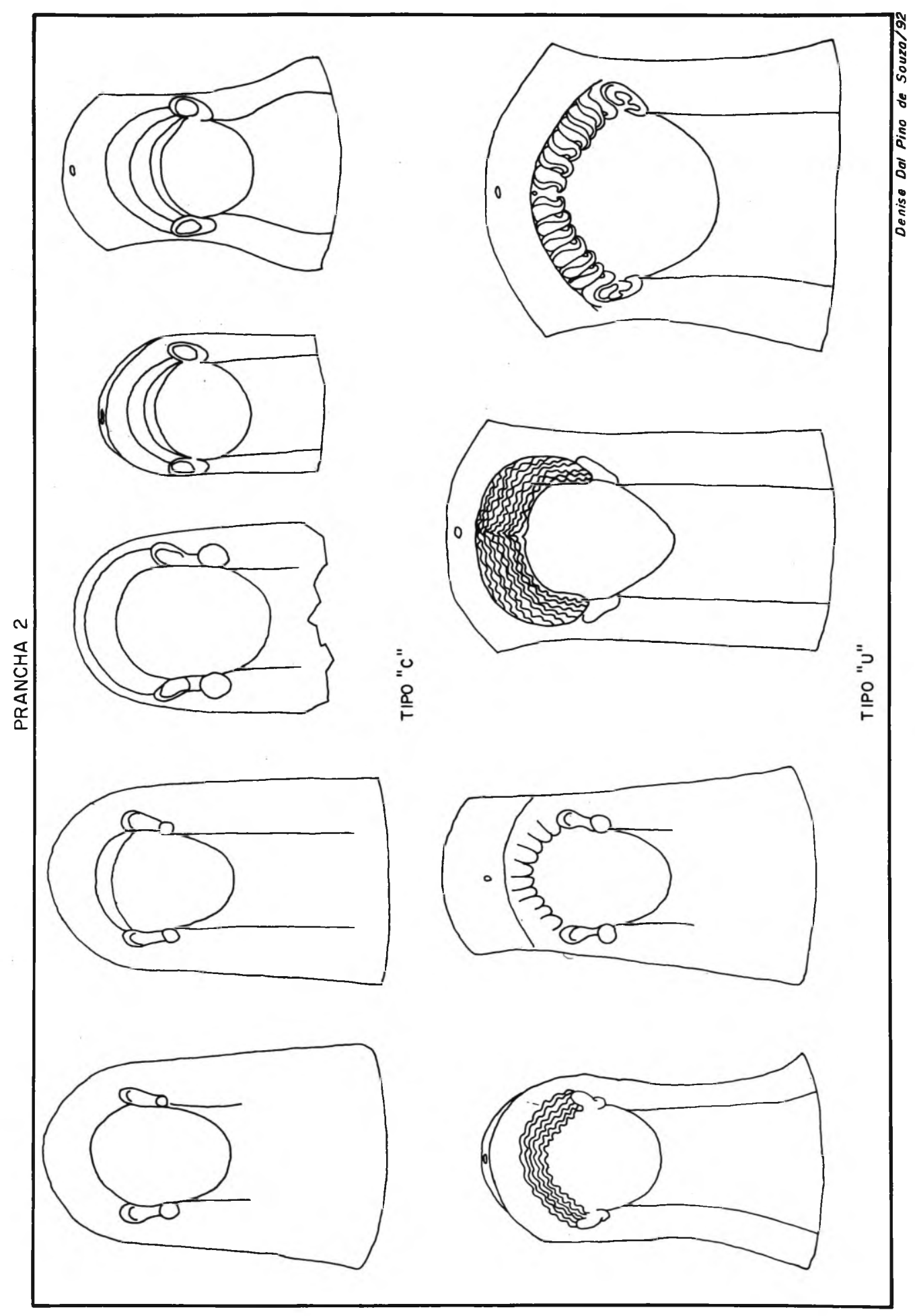


HIRATA, E. F. V. Os prótomos femininos de Gela: uma proposta de interpretaçảo. Rev. do Museu de Arqueologia e Etnologia, S. Paulo, 2:49-61, 1992.

PRANCHA 3

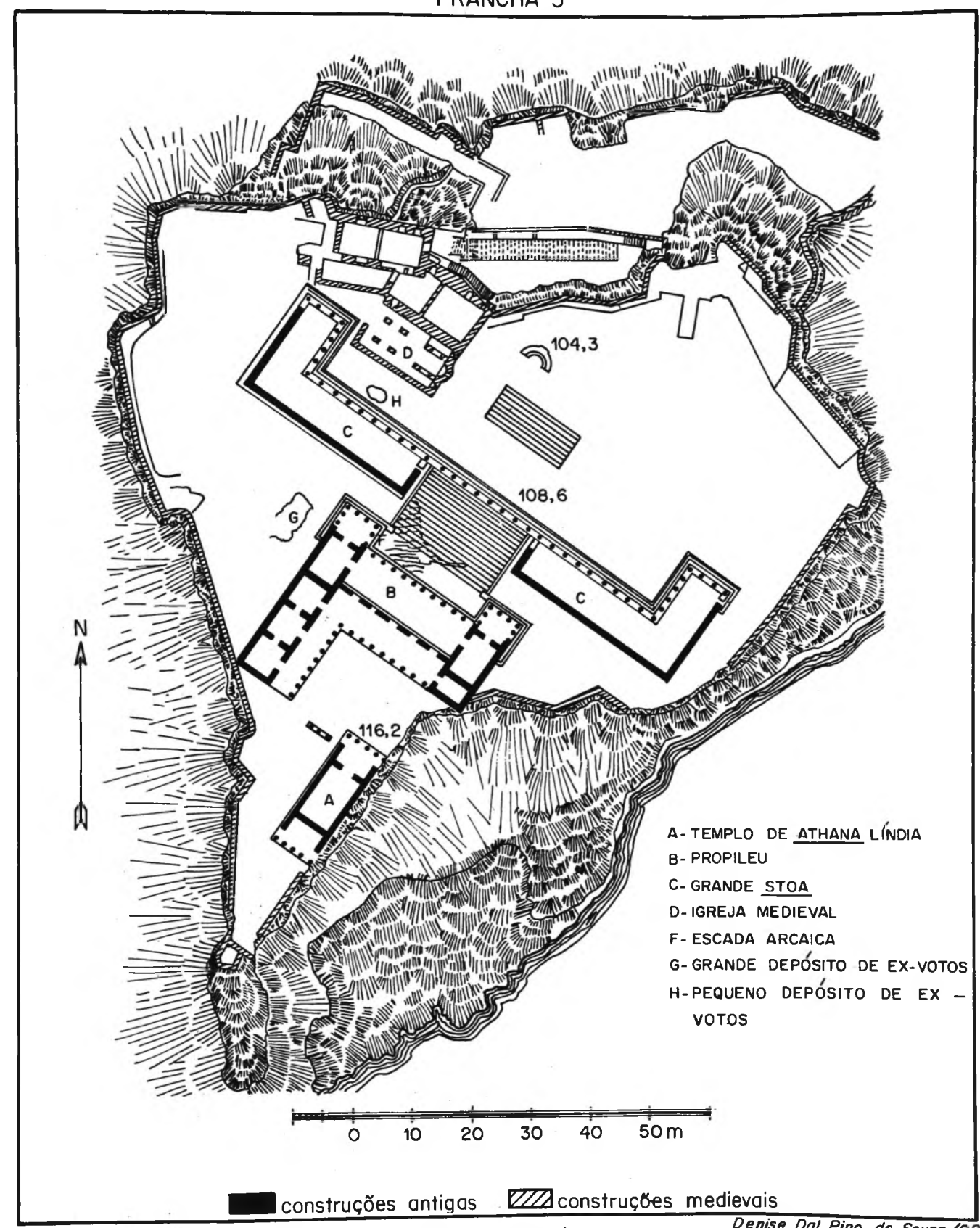

ACRÓPOLE DE LINDOS - (Blinkenberg, Lindos) 


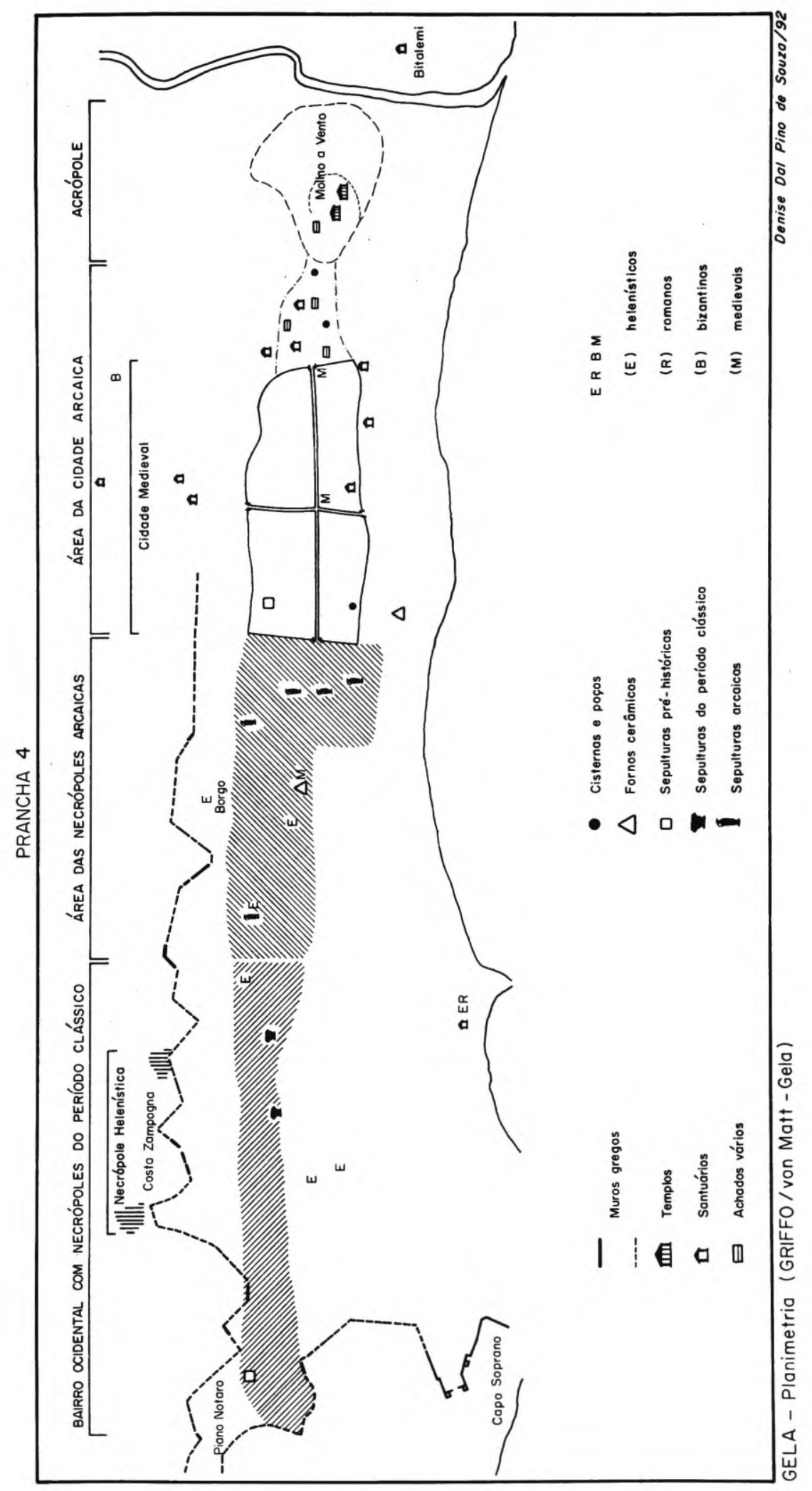




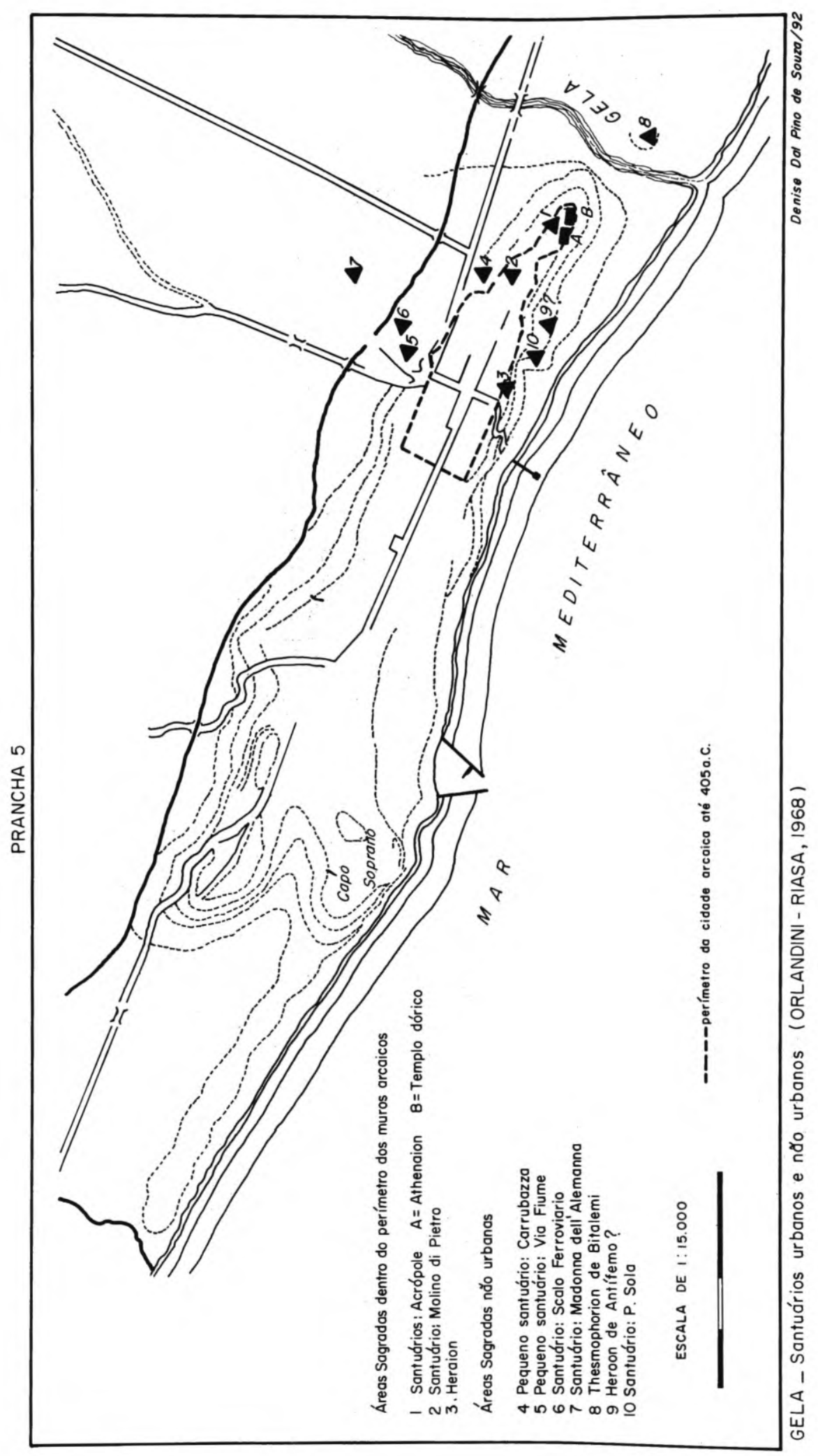


HIRATA, E. F. V. Os prótomos femininos de Gela: uma proposta de interpretaçào. Rev. do Museu de Arqueologia e Etnologia, S. Paulo, 2:49-61, 1992.

HIRATA, E. F. V. The feminine protomai from Gela: an interpretation proposal. Rev. do Museu de Arqueologia e Etnologia, S. Paulo, 2:49-61,1992.

ABSTRACT: This study confronts the spatial distribution patterns of the Greek protomai recovered at Gela - colony founded by oecists from Rhodes and Crete - and Rhodes. The analysis of the contextual evidence points out the specialized function assumed by this artifact at Gela and the Geloan hinterland: the protome is one of the most frequent agalma found in Demeter's sanctuaries. The funerary function customary attested in Rhodian sites (Camiros, Iálisos) is insignificant in Sicily.

UNITERMS: Greek Mask Protomo. Mediterranean Archaeology. Religion. Sicily. Gela. Chthonian divinities.

\section{Referências bibliográficas}

BARRA BAGNASCO, M. - Protomi in terracotta da Locri Epizefiri. Contributo allo studio della scultura arcaica in Magna Grécia. Turim, 1986.

BELL, M. - The terracotras. Morgantina Studies. Vol. I. Results of the Princeton University Archaeological Expedition to Sicily. Princeton, 1981.

BISI, A.M. - Motivi Sicelioti nell'Arte Punica di Età Ellenistica. Arch. Class, Roma, XVIII, 1: 41-53, 1966.

BLINKENBERG, C.L. - Lindos. Fouilles et découvertes (1902-14). Les petits objets. Berlin - Copenhagen, 193:

CIACERI, E. - Culti e miti nella storia dell 'antica Sicilia. Catânia, 1911.

CLARA RHODOS. Studi e materiali publicati a cura dell'Istituto Storico-archeologico di Rodi. 1928-41.

CROISSANT, F. - Les protomés féminines archaiques. Recherches sur les représentations $d u$ visage dans la plastique grecque de 550 a 480 av. J. C. BEFAR, 250, Paris, 1983.

CULICAN, W. - Some Phoenician Masks And Other Terracottas, Berytus 24: 47-87,1975-76.

FERRI, S. - Archeologia della Protome, Annali Della Scuola Normale Superiore Di Pisa, s. 2, 2: 147-158, 1938.

GRIFFO, P.; MATT, L. von - Gela. Schicksal einer griechischen Stadt Siziliens. 1964.

KILMER, M. - The shoulder bust in Sicily and South and Central Italy; a Catalogue and Materials for Dating. Studies in Mediterranean Archeology, LI, Göteborg 1977.

LAUMONIER, A. - Les Figurines de Terrecuite. Éxploration Archéologique de Delos par L'Ecole Française D'Athènes, Fasc. XXIII, Paris, 1956.

LEVI, D. - Gli scavi di lasos, Annuario della Scuola
Arqueologica di Atene e delle Missioni italiane in Oriente, 45-46: 537-590, 1967-68.

ORLANDINI, P. - Le Thesmophorion di Bitalemi e il culto delle Divinita Ctonie a Gela, KOKALOS XII: 8-35, 1966.

- Gela. Topografia dei santuari e documentazione archeologica dei culti. Rivista dell' Istituto Nazionale d'Archeologia e Storia dell'Arte, ns. XV: 20 66, 1968.

PICARD, C. - "Sacra Punica. Étude sur les masques et les rasoirs de Carthage". Karthago, 13: 7-115, 1965-66.

ROBINSON, D. M. - Excavations at Olynthus. Part VII: The Terracottas of Olynthus found in 1931. Baltimore, 1933.

ROLLEY, CL. - III. Demėter et Koré: le Thesmophorion de Thasos, Bulletin de Correspondance Hellénique, LXXXIX, (II): 441-83, 1965.

SGUAITAMATTI, M. - L'offrante de porcelet dans la coroplathie géleènne. Étude typologique. Zurique, 1984.

SMITH, H.R.W. - A goddess from Lebadeia. Hesperia, SUPPL. 8: 353-360, 1949.

UHLENBROCK, J. E. - The protomai from Gela: History, Chronology and Style. Tese de doutoramento, N. York State University, 1978.

UFFORD, L. Q. van - Les terres cuites Siciliennes. Assen, 1941

WHITE, D. - Demeter's Sicilian cult as a political instrument. GRBS, 5: 261-279, 1964.

WHITE, D. The post-classical cult of Malophoros at Selinus, American Journal of Archaelogy, 171 (4): 335-352, 1967.

ZUNTZ, G. - Persephone. Three Essays on Religion and Thought in Magna Grecia. Oxford, 1971. 
